\title{
Comparing syntactic development in adolescents' written texts
}

Maria Liakou, Georgia Andreou, Fotini Anastassiou

Department of Special Education, University of Thessaly, Greece/ Hellenic Open

University, Greece

https://doi.org/10.36505/ExLing-2017/08/0017/000319

\begin{abstract}
The aim of this study was to investigate whether adolescents reach the linguistic level corresponding to their age and to compare their syntactic abilities in written narrative and non narrative texts. The results showed that generally older adolescents had better syntactic abilities compared to smaller ones. However, an unexpected linguistic development was observed in the smaller age group and in non narrative texts, showing that the production of complex texts may lead to unexpected linguistic levels.
\end{abstract}

Key words: syntactic development, written texts, adolescence

\section{Introduction}

Linguistic processes and syntactic skills continue to grow over the adolescents' years. The central focus of our study is adolescents with "typical language development", and this term refers to the language someone learns under normal circumstances during the period of eleven or twelve and early adulthood (Andreou, Liakou, Galantomos 2017; Beers, Nagy 2009, 2011; Nippold 2007; Paul 2001). During this period, adolescents learn to read and write narrative and non narrative texts among others. Narrative texts are those that reflect mostly past experiences and humans' actions. Non narrative texts focus on the development of arguments and information without relying on narration (Georgakopoulou, Goutsos 1999). An important marker of later syntactic development is clausal density (or subordination index), which increases during the adolescent years (Nippold, Hesketh, Duthie, Mansfield, 2005). Clausal density is defined as "the average number of clauses (main and subordinate) per T-unit" and it is measured by summing the total number of clauses (independent and subordinate) and dividing by the total number of $\mathrm{T}$-units produced in a language sample (Scott 1988). The samples are broken into T-units, defined as an independent clause with any accompanying subordinate (dependent) clauses (Hunt 1970).

\section{Purpose of the study}

Based on the above, the aim of this study was to compare adolescents' ability to produce a number of T-units and clauses in relation

ExLing 2017: Proceedings of 8th Tutorial and Research Workshop on Experimental Linguistics, 19-22 June, Heraklion, Crete, Greece 
to their age, examining the differences between the two genres. Given the difficulty of non narrative texts, it was also predicted that both groups would use more clauses in narrative than in non narrative texts.

\section{Method}

Our research took place in public, urban high schools in Greece. Our sample consisted of two groups of 300 typically developing adolescents $(\mathrm{N}=300)$. The average age of the first group was $14.5(\mathrm{~N}=150$ early adolescents) and of the second group was 16.6 ( $\mathrm{N}=150$ late adolescents).

The students were asked to write two different texts, one narrative and one non narrative on the topic of racism, following the instructions given, which were the same for both groups of high-school students. In total, we analyzed 600 written texts, half of them being narrative and half non-narrative.

The Mann-Whitney U Test was used to detect possible differences in written texts between early and late adolescents and the Wilcoxon SignedRank Test was used to compare two sets of scores between narratives and non narratives texts that were written by the same participant. SPSS 15 was used for our statistical analysis and Monte Carlo simulation methods were used to obtain the p-value. When the p-value is less than the significance level a $(\mathrm{a}=0.05)$, the result is said to be statistically significant.

\section{Results}

The statistical analysis of Mann-Whitney (see tables 1,2) revealed that there is a statistically significant difference in non-narrative texts between the two groups of adolescents in the: a) total clauses of texts and b) clausal density.

Table 1. Mean percentage of text T-units, text clauses and clausal density by age group (Early vs Late adolescents) in narrative texts.

\begin{tabular}{|l|l|l|l|}
\hline Type of Adolescents & Total T-units of Text & Total Clauses of Text & $\begin{array}{l}\text { Clausal } \\
\text { Density }\end{array}$ \\
\hline Early adolescents & 7.4 & 22.0 & 3.2 \\
\hline Late adolescents & 7.4 & 21.8 & 3.1 \\
\hline p-value & $0.772(\mathrm{NS})$ & $0.689(\mathrm{NS})$ & $0.984(\mathrm{NS})$ \\
\hline
\end{tabular}

Table 2. Mean percentage of text T-units, text clauses and clausal density by age group (Early vs Late adolescents) in non-narrative texts.

\begin{tabular}{|l|l|l|l|}
\hline Type of Adolescents & Total T-units of Text & Total Clauses of Text $\begin{array}{l}\text { Clausal } \\
\text { density }\end{array}$ \\
\hline Early adolescents & 7.3 & 21.8 & 3.2 \\
\hline Late adolescents & 7.3 & 18.6 & 2.6 \\
\hline p-value & $0.637(\mathrm{NS})$ & $\mathrm{p}=0.001(\mathrm{~S})$ & $\mathrm{p}=0.001(\mathrm{~S})$ \\
\hline
\end{tabular}


The statistical analysis of Wilcoxon (see Figures 1 \& 2) showed a statistically significant difference between the two genres in the a) total clauses of text of late adolescents and b) clausal density of late adolescents.

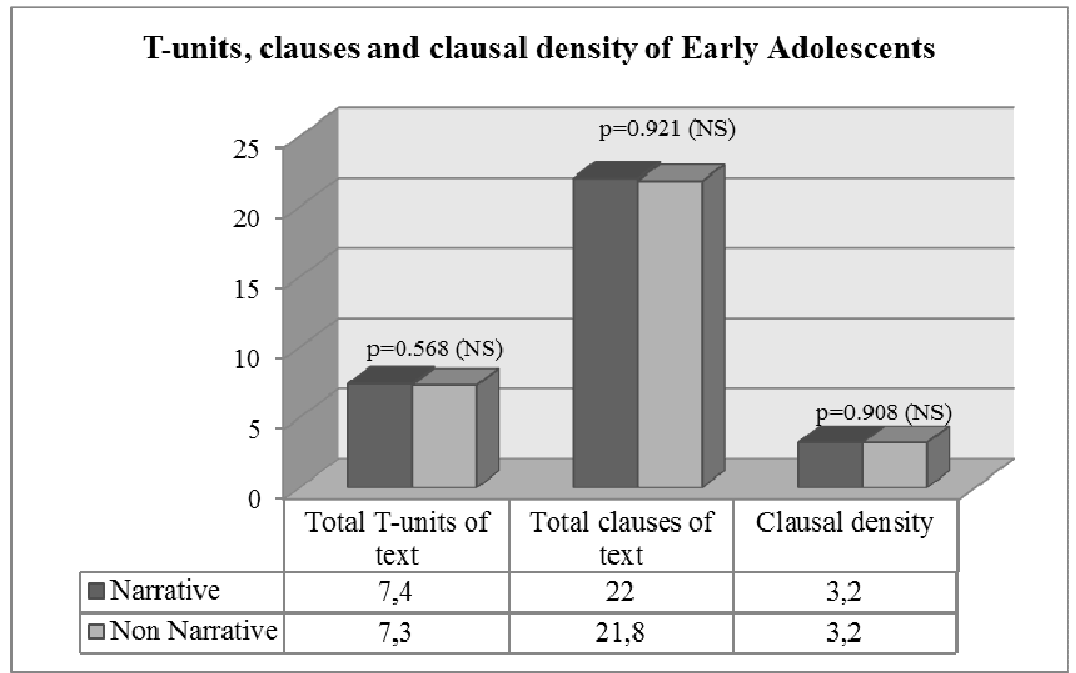

Figure 1. Mean proportion of T-units of text, total clauses of text and clausal density in early adolescents' texts (S: significant, NS: non significant).

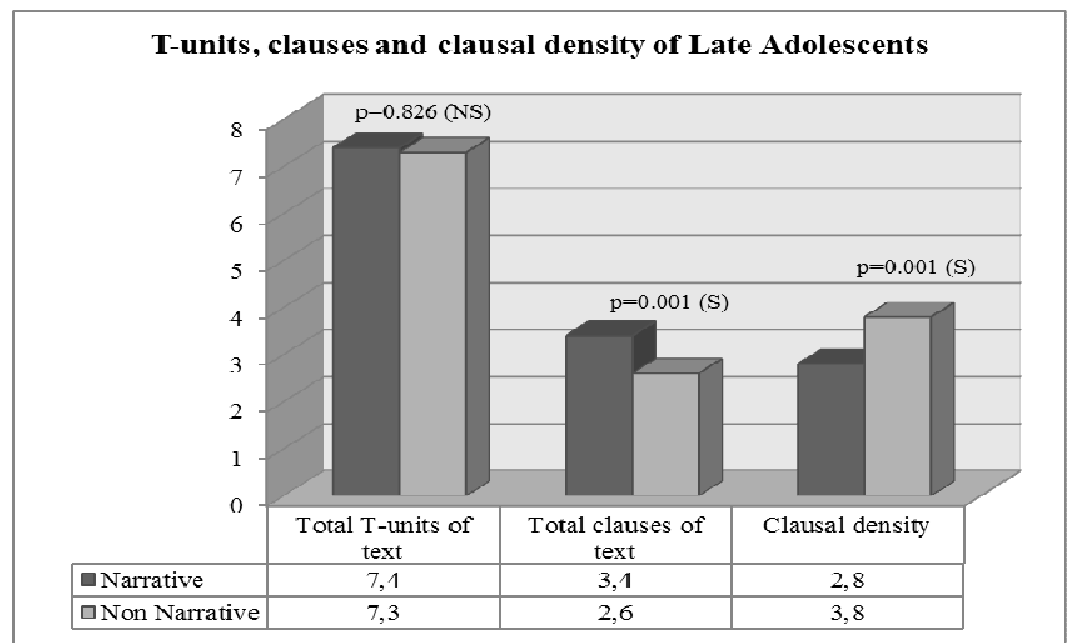

Figure 2. Mean proportion of T-units of text, total clauses of text and clausal density in late adolescents' texts (S: significant, NS: non significant). 


\section{Conclusions - Discussion}

The results showed great syntactic complexity in narrative and non narrative texts for all age groups. Early adolescents functioned at higher levels of linguistic development than late adolescents regarding all of the criteria. So, our results showed that some students functioned at lower levels of language development corresponding to their age, whereas others reached an advanced linguistic level with considerable syntactical skills. In addition, an unexpectedly high syntactic development of the adolescents in our sample was observed, both in terms of age and the two types of texts examined.

So, syntactic complexity increases during adolescence, marked especially by a growth in the use of clauses (Andreou, Liakou, \& Galantomos, 2017). Generally, earlier studies revealed a complex syntax in the areas of narrative and non-narrative texts as well (Beers \& Nagy, 2009, 2011; Nippold, 2007; Nippold et.al., 2005).

\section{References}

Andreou, G., Liakou, M. \& Galantomos, I. (2017). Differences in syntactic development in adolescence. European Journal of Language Studies, 4 (2), 6-11.

Beers S. F. \& Nagy W. E., (2011). Writing development in four genres from grades three to seven: syntactic complexity and genre differentiation. Reading and Writing, 24, 183-202.

Beers S. F. \& Nagy W. E., (2009). Syntactic complexity as a predictor of adolescent writing quality: Which measures? Which genre? Reading and Writing, 22, 185200.

Georgakopoulou, A. \& Goutsos, D. 1999. Text and Communication. Athens: Ellinika Grammata.

Hunt, K. W. (1970). Syntactic maturity in school children and adults. Monographs of the Society for Research in Child Development, 35 (Serial No. 134, No. 1), 167.

Nippold, M. 2007. Later Language Development: School-Age Children, Adolescents, and Young Adults. Austin, TX, Pro-Ed.

Nippold M.A., Hesketh L.J., Duthie J.K. \& Mansfield T.C., (2005a). Conversational versus expository discourse: A study of syntactic development in children, adolescents, and adults. Journal of Speech, Language, and Hearing Research, 48, 1048-1064.

Paul, R. 2001. Language Disorders from Infancy through Adolescence (Second Edition). United States of America, Mosby.

Scott, C. M. (1988). Spoken and written syntax. In M. A. Nippold (Ed.), Later language development: Ages nine through nineteen (pp. 49-95). Austin, TX: ProEd. 